\title{
Recreational drug use and sport: Time for a WADA rethink?
}

\author{
Ivan Waddington $^{\mathrm{a}, \mathrm{b}, *}$, Ask Vest Christiansen ${ }^{\mathrm{c}}$, John Gleaves ${ }^{\mathrm{d}}$, \\ John Hoberman ${ }^{\mathrm{e}}$, Verner Møller ${ }^{\mathrm{c}}$ \\ a Norwegian School of Sport Sciences, Department of Culture and Society, Sognsveien 220, 0806 Oslo, Norway \\ ${ }^{\mathrm{b}}$ University of Chester, UK \\ ${ }^{c}$ Department of Public Health, Section for Sport Science, Aarhus University, Dalgas Avenue 4, DK-8000 Aarhus C, Denmark \\ d Department of Kinesiology, California State University, Fullerton, 800 North State College Boulevard, Fullerton, CA 92831, USA \\ e Department of Germanic Studies, University of Texas, 2505 University Avenue, Mailcode C3300, Austin TX 78712-1802, USA
}

\section{A R T I C L E I N F O}

\section{Article history:}

Received 1 December 2012

Received in revised form 23 April 2013

Accepted 23 April 2013

\section{Keywords:}

WADA

Recreational drugs

Fair play

Health

Marijuana

Performance enhancement

\begin{abstract}
A B S T R A C T
This paper examines current policies towards drug use in sport to evaluate their appropriateness. The focus is on the World Anti-Doping Agency's (WADA's) attitudes and policies towards athletes' use of recreational drugs. Since recreational drugs such as marijuana are not performance-enhancing, one of the most frequently used arguments to justify doping controls - that those involved in drug use derive an unfair advantage over other competitors - cannot be used to justify controls on the use of such drugs. Given this, it is suggested that the attempt to control the use of marijuana within a sporting context is best understood in terms of the growing concern about drug 'abuse' within the wider society. The paper further suggests that the WADA has used the 'spirit of sport' argument to reach beyond traditionally accepted sporting concerns. In this regard, WADA is using anti-doping regulations to police personal lifestyle and social activities that are unrelated to sporting performance. On this basis, it is concluded that WADA's focus and resources should return to enforcing sporting values related to doping rather than policing athletes' lifestyles, and it is therefore suggested that the ban on marijuana and similar recreational drugs should be lifted.
\end{abstract}

(c) 2013 Elsevier Ltd. All rights reserved.

\section{Introduction}

The use of performance-enhancing substances within the sporting context is a very longstanding phenomenon, for people involved in sport and sport-like activities have used performance-enhancing drugs for some two thousand years (Donohoe \& Johnson, 1986, pp. 2-3; Houlihan, 2002, p. 33; Verokken, 2005, p. 29). It is only very recently - specifically since the introduction of anti-doping regulations and doping controls from the 1960s - that this practice has been regarded as unacceptable. For all but the last five decades, those involved in sports have used performance-enhancing drugs without infringing any rules and without the practice giving rise to highly emotive condemnation and stigmatization. The juxtaposition of these two facts - the acceptance of the use of drugs within the sporting context for almost two thousand years, and the fact that anti-doping policies only developed from the 1960s - highlights points of fundamental importance: that current attitudes and policies towards drug use are very recent and do not represent eternal and unchanging sporting values, an 'essence' of sport;

\footnotetext{
* Corresponding author at: Norwegian School of Sport Sciences, Department of Culture and Society, Sognsveien 220, 0806 Oslo, Norway. Tel.: +47 441162730066.

E-mail address: ivan.waddington@ntlworld.com (I. Waddington).
}

rather, they were developed under specific social circumstances and expressed particular concerns at that time. ${ }^{1}$ Given this situation, it may be appropriate to re-examine our current attitudes towards drug use from time to time to see whether they are still appropriate. That is the object of this article.

\section{The rationale for doping control}

As several authors (e.g. Black, 1996; Kayser, Mauron, \& Miah, 2005) have noted, since anti-doping controls were introduced from the 1960s, the two major justifications for the ban on the use of drugs in sport have been those relating to the protection of the health of athletes and to the maintenance of fair competition, the so-called 'level playing field'. These were, for example, the two key arguments against doping which were cited in the Olympic Movement Anti-Doping Code (IOC, 1999). More recently, the same two arguments were recited in the Anti-Doping Policy adopted by the Australian Sports Commission (ASC) in 2004, which stated that the Commission was opposed to the use of prohibited substances or

\footnotetext{
1 The broader social circumstances, including the growing public concern about drug use within the wider society in the 1960s, are analyzed in Waddington and Smith (2009, chapter 3).
} 
methods since this was 'contrary to the ethics of sport and potentially harmful to the health of Athletes' (ASC, 2004, p. 4). The same two arguments are also cited in the preliminary words to the Danish 'Act on Promotion of Doping-Free Sport', and they thus serve as the juridical base for this Act (Evald, 2009; Retsinformation, 2004).

These two key arguments had, a few years earlier, been set out particularly clearly in a 1996 policy statement on doping by the Great Britain Sports Council:

The Sports Council condemns the use of doping substances or doping methods to enhance artificially performance in sport. Doping can be dangerous; it puts the health of the competitor at risk. Doping is cheating and contrary to the spirit of fair competition. (Sports Council, 1996, p .7, emphasis added)

These two arguments - that drug use may damage the health of athletes and that it is a form of cheating - have, ever since the introduction of anti-doping regulations in the 1960s, been consistently cited as the major justifications for the ban on the use of drugs (Dimeo, 2007, p. x). ${ }^{2}$

These arguments, it might be noted, have not met with universal acceptance. Several authors have argued, for example, that the 'fair play' argument is fundamentally flawed since athletes do not compete on a level playing field; for example, the access which athletes have to key resources - such as financial support, training facilities, the support of experts in exercise physiology, biomechanics, nutrition, and sport psychology - varies enormously between rich and poor countries. ${ }^{3}$

Critics have also pointed to several inconsistencies in the health based arguments: that there are many drugs on the banned list which appear to have few, if any, side effects; that many drugs which are legally used within sport have well documented and potentially serious side effects; and that there is a powerful argument which suggests that elite sport, because of the intensity of modern training and competition, is itself damaging to the health of athletes (O'Leary, 2001; Savulescu and Foddy, in House of Commons, 2007; Waddington \& Smith, 2009). Many scholars would not disagree with Houlihan's considered judgment, in his book for the Council of Europe, that the 'rationale for banning drugs constructed around fairness fails to provide the desired watertight basis for policy', while 'relying upon health-related arguments to provide a basis for anti-doping policy ... is not possible' (Houlihan, 2002, p. 132).

However, if these relatively longstanding arguments underpinning the ban on the use of drugs are less than watertight, the waters have become considerably more muddied by the addition, from the late 1990s, of a third and much more contentious argument which provides a rationale for the ban on the use of recreational drugs such as marijuana. Let us examine changing attitudes and policy towards the use of recreational drugs by anti-doping organizations.

\footnotetext{
2 We might note that those within the sporting world have for many years made efforts to regulate the safety of play for athletes and fairness as sporting issues. From regulations on equipment and eligibility, to pre-contest qualifying requirements, regulatory bodies within sport have passed rules designed to promote fairness. At the same time, health concerns have led to the introduction of helmet rules and other regulations designed to protect athletes' health during competitions. Thus the two rationales for banning doping - health and fairness - are firmly situated within the ethos of sport.

${ }^{3}$ Many authors have argued that the 'fair play' argument is inherently circular and have suggested that fair play is not a rationale for having the bans but, rather, for enforcing the bans once they exist. Given the previous point that athletes do not start on a level playing field, it is not clear that allowing athletes to use drugs would make the field more unlevel than is the case in the current situation, in which athletes with financial and other means are allowed to access key resources which may not be available to other athletes.
}

\section{Changing policy towards recreational drug use}

It is instructive to note that, at least until fairly recently, many sporting bodies, including the IOC, took a relatively tolerant attitude towards the 'social' use of drugs such as marijuana and cocaine, the latter of which may have potentially dangerous side-effects and both of which - unlike many of the drugs on the list of banned substances - are illegal in many countries. From the mid-1990s, many sporting bodies began to take a less tolerant attitude towards the use of 'social' drugs. This policy shift is examined in more detail later; for the moment, we wish to examine the debate around the use of 'social' drugs in sport in the period up to the 1990s, for this debate was in some respects very revealing about the underlying rationale for banning the use of some drugs but not others.

The recent history of marijuana use within the sporting context is particularly instructive. There was no testing for marijuana at any Olympic Games before 1988. However, prior to the Seoul Olympics of that year, the IOC was asked by several countries to test for marijuana 'to see whether there was a problem among top-class competitors'. A small number of competitors at those Games were found to have smoked marijuana recently. The possession of marijuana is a criminal offence in Korea, but the names of the athletes involved were not released because the use of cannabis was at that time neither banned nor restricted by the IOC. Moreover, the rationale for this was perfectly clear; in the words of the then-president of the IOC's Medical Commission, Prince Alexandre de Mérode, 'Marijuana does not affect sporting performance'. A similar position was expressed by Professor Arnold Beckett, a leading member of the IOC Medical Commission, who stated quite unambiguously that 'If we started looking at the social aspect of drug-taking then we would not be doing our job' (Times, 14 September 1988).

Some sporting bodies at the time took a similarly tolerant position in relation to the use of cocaine which, although technically a stimulant and therefore on the list of prohibited drugs, has seen its performance-enhancing value markedly decrease as other more powerful substances have taken its place. Moreover, studies of cocaine's ergogenic effects in humans 'provide little reproducible evidence that cocaine in any of its tested forms improves performance' (Conlee, 2002, p. 286). Given this situation, it is not perhaps surprising that in today's sporting world, cocaine is used mainly for 'recreational' purposes. It was presumably this latter consideration which, during the 1980s, led the tennis authorities at the Wimbledon Championships to adopt a similarly tolerant attitude towards tennis players found to be using cocaine. Thus when tests for cocaine were introduced for male tennis players at Wimbledon in 1986, it was revealed that no action would be taken against those who tested positive; instead, psychiatric help would be offered (Times, 14 September 1986).

However, in 1989, the IOC signaled a change in its position in relation to one of the most widely used recreational drugs, marijuana. The result of this policy shift was that, while marijuana was not at that time added to the list of drugs which were banned by the IOC, it was added to the list of drugs which were 'subject to certain restrictions', and different governing bodies in sport specified different regulations in relation to marijuana (Council of Europe, 1989; IOC, 1989). This was a significant change, not least because it opened the door to the monitoring of the non-sporting lifestyles of athletes.

This shifting attitude on the part of the IOC was also reflected in changes at the national level. In Britain, for example, athletes have since the early 1990s been tested for marijuana and in 1996 the Sports Council expressed concern at the growing number of athletes testing positive for marijuana. In 1992-1993 and in 1993-1994 there were just two positive tests each year in Britain for marijuana use, but in 1994-1995 the figure increased to ten and there were a further ten positive tests in 1995-1996. In the 
annual report from its Doping Control Service in 1996, the Council held that the 'increasing number of findings of social drugs is of concern and will require further efforts in drug prevention partnerships to address the problem' (Sports Council, 1996, p. 26). The Sports Council's statement was indicative of the changing attitude towards the use of recreational drugs within sport and provided a striking contrast with the statement made by Professor Beckett in 1988 , as noted earlier, in which he said that if the IOC and governing bodies became involved in 'the social aspect of drug taking then we would not be doing our job'. Since then, the attitude of sporting bodies towards the use of marijuana has further hardened and it is now listed as a banned drug in the Prohibited List of WADA (WADA, 2007).

As attitudes and policies towards the use of social drugs have changed, so too has the rationale for the inclusion of drugs on the banned list. As we noted earlier, the two traditional arguments which have been used to justify the ban on the use of drugs have been that their use may damage the health of athletes and that it is cheating. But the increasingly hard line towards recreational drug use which was being adopted by anti-doping agencies from the 1990s required the adoption of a third, and quite new, rationale.

In its annual report for 1997-1998, the Ethics and Anti-Doping Directorate of the UK Sports Council referred in its policy statement both to the health-based arguments and to those relating to cheating, but it added a third argument - that drug use 'is harmful to the image of sport' (Sports Council, 1998a, p. 3). This argument has subsequently been echoed by some governing bodies of English sport; for example England Hockey (2005) has stated that 'drug misuse... damages the image of Hockey as a sport.' More recently, increasing reference has been made to the idea that the use of drugs is 'counter to the "spirit" of sport' (House of Commons, 2007, p. 6) or, as the World Anti-Doping Agency Code, first adopted in 2003, put it, drug use 'violates the spirit of sport' (WADA, 2003, p. 16).

Such vaguely defined notions as the 'image' or the 'spirit' of sport have a 'catch all' quality which is of critical importance since it provides a rationale for banning recreational drugs which may be difficult to ban on other grounds. ${ }^{4}$ Let us examine this issue.

It is important to note in this context that the use of recreational drugs such as marijuana raises quite different issues from those raised by the use of drugs such as anabolic steroids or stimulants for, unlike the latter, marijuana is not a performance-enhancing drug. Moreover, this fact, as we noted earlier, has been explicitly acknowledged by sporting bodies. However, since marijuana is not a performance-enhancing drug, it follows that one of the arguments most frequently used to justify doping controls - that those involved in drug use derive an unfair advantage over other competitors and are therefore cheating - cannot be used to justify controls on the use of marijuana. Given that this is the case, it might be suggested that the attempt to control the use of marijuana within a sporting context is best understood, not in terms of considerations which are specific to sport but, rather, in terms of the growing concern about drug 'abuse' within the wider society. This point leads us into a consideration of some of the broader issues associated with drug use and doping control in sport. Before we

\footnotetext{
${ }^{4}$ In the WADC 'the spirit of sport' is synonymous with the "intrinsic value of sport". "The spirit of sport" as stated in the code, is the celebration of the human spirit, body and mind, and is characterized by the following values: ethics, fair play and honesty, health, excellence in performance, character and education, fun and joy, teamwork, dedication and commitment, respect for rules and laws, respect for self and other participants, courage, community and solidarity: The fuzziness of this characterization of 'the spirit of sport' appears from the fact that almost all of these 11 descriptors are compatible with doping. And those that are not, are not compatible with elite sport either. Perhaps because it is not obvious that the characterization gets the messages across, the code subsequently emphasises that: “Doping is fundamentally contrary to the spirit of sport(WADA, 2009, p. 14).
}

consider these broader issues however, it will be useful to return to a brief examination of the more traditional argument that doping is cheating.

\section{Doping as cheating}

Drug use, like any other action which is against the rules and which is designed to gain an advantage, is unambiguously cheating; that much is clear. But it is also clear that drug use is not like other forms of cheating, for both the public reaction - and, we would suggest, the reaction of regulatory bodies within sport - is more emotive and more punitive than is the case with other forms of cheating. As Richard Williams, writing in the aftermath of the 1998 Tour de France scandal pointed out, doping 'is generally felt to be the worst of sporting crimes' (Guardian, 1 August 1998) - it appears to be regarded as an even bigger threat to sport than match fixing (Sparre, 2011) $)^{5}$ - and the strength of feeling which drug use in sport arouses can be seen in recurring demands for increasingly lengthy, even life, bans and heavy fines for those who test positive for the use of drugs. As the editor of the British Medical Journal has pointed out, 'We get terribly excited about the use of drugs in sport' (McCrory, 2007, p. 1). How then, do we account, for the highly emotive and punitive reaction to drug use?

The fact that drug use is conventionally regarded as a form of cheating might be held to constitute an adequate explanation of why the practice is generally regarded as so objectionable and why it arouses such strong emotions. However, such simplistic answers often obscure more than they reveal. If the generally highly emotive reaction to the use of drugs in sport arises primarily from the fact that drug use constitutes a form of cheating, then one might reasonably expect an equally strong and emotive reaction to the many other forms of cheating in sport. Is this, however, what we find? In all sports there are actions which involve breaches of the rules and which constitute clear forms of cheating, but which do not arouse the same emotional response nor the same demands for swingeing punishments. One could cite in this connection forms of cheating such as handling the ball or pushing an opponent in soccer, playing the ball on the ground with the hands after a ruck has formed in Rugby union, 'holding' or 'pass interference' in American football, and holding an opponent or deliberate blocking fouls in basketball. All of these actions constitute attempts to gain an unfair advantage over one's opponents - that is, they are all forms of cheating but they do not, save in quite exceptional circumstances, evoke the same kind of emotional response associated with the specific form of cheating which involves the use of drugs. In the average soccer or rugby match, for example, there may be many incidents of foul play, but the usual response to each incident is that the appropriate penalty is awarded against the offending player who may also be gently or more severely admonished by the referee. However, he or she is not normally publicly accused of undermining the very foundation of the sport and there are no demands for lifelong bans for a soccer player who controls the ball with his/her hand, or for the rugby player who tackles a player who does not have the ball. The use of drugs, then, is not treated just like any other form of

\footnotetext{
5 That doping should generally be regarded as a bigger threat to sport than match fixing is interesting, not least because match fixing is logically a bigger threat since it represents an attempt to predetermine the outcome of a sporting contest in advance of the competition. In this regard, successful match fixing effectively abolishes sporting competition, while it may be argued that athletes' use of performance enhancing drugs embraces competition and the associated desire to win in that it demonstrates a willingness to compete to the absolute limit. In this sense it might be argued that, as Coakley (2007, pp. 175-178) has noted, doping may be considered as a form of behaviour which arises not from underconformity to the norms of sport but from an overconformity to one of the central values of modern sport, namely the value attached to winning.
} 
cheating, for the public response to the use of drugs in sport is both more emotive and more forceful than the response to most other forms of cheating. How, then, do we account for these very different responses to the different forms of cheating?

\section{Drugs in sport and drug use in the wider society}

We suggest that the strong emotions aroused by drug use in sport cannot be adequately understood without reference to processes within the wider society which have little to do directly with sport. In this connection, it is suggested that public attitudes towards the use of drugs in sport have been 'contaminated', as it were, by the widespread public concern about the possession, sale and 'abuse' of controlled drugs in society more generally. The use of controlled drugs, it should be noted, is not only illegal in most Western societies but is also widely held to be associated with other forms of criminal activity and with a wide variety of other social problems, with physical and psychological addiction, with dangers to the 'moral health' particularly of young people, and with severe risks to health including the risk, in the case of injecting drug users, of hepatitis and, more recently and even more anxiety-arousing, AIDS. We suggest that the generally emotive response to the use of performance-enhancing drugs in sport is to be explained, at least in part, by reference to the widespread public concern - 'moral panic' would not be too strong a term - relating to other patterns of 'drug abuse' within society more generally. ${ }^{6}$

It is therefore important to locate the concern about drugs in sport within the context of this wider concern about the use of controlled drugs in society more generally; more specifically, it is important to recognize how public attitudes and anxieties towards the use of controlled drugs in society generally have 'spilled over' into the sports arena and have influenced - and continue to influence - anti-doping policies in sport.

This 'spillage' of public anxieties about drugs in general into the sporting arena can perhaps be most clearly illustrated by reference to policy statements by the UK Sports Council, which has spelt out the arguments against the use of recreational drugs rather more explicitly than have other organizations, including WADA. As we noted earlier, in the late 1990s, the Sports Council added a third anti-doping argument to the more conventional arguments based on considerations concerned with the health of athletes and with cheating; this third argument stated that 'drug misuse ... severely damages the image of sport, even when the motivation to use drugs is not to improve sporting performance' (Sports Council, 1998b, p. 1; emphasis added). This third rationale for anti-doping policies was clearly designed to provide a justification for controls on marijuana and other recreational drugs.

However, what is particularly striking about this rationale is that it has little, if anything, to do with values which are specific to the sports context - people who use marijuana cannot, for example, be accused of seeking an unfair advantage - while it draws heavily upon the negative images associated with drug use in society more generally. This is made explicit when the Sports Council spells out the two main ways in which, it suggests, the use of 'recreational' drugs might 'damage the image of sport'. The Sports Council points out, firstly, that possessing or supplying drugs such as marijuana is illegal and the argument here thus relates not to sporting values,

\footnotetext{
${ }^{6}$ One indication of a moral panic is that the punishment imposed for an offence is disproportionate to the seriousness of the offence. In this regard it might be noted that in many states of the USA possession of marijuana and other illegal drugs was, between 1959 and 1968, the most heavily penalized crime, with a twenty year mandatory minimum jail sentence. By contrast, the mandatory minimum jail sentence for first degree murder was fifteen years, and for rape it was ten years (see Whitebread, 1995).
}

but - and this is a significant departure from previous rationales to the criminal law. Moreover, this argument is particularly problematic since possessing and supplying marijuana is not illegal in all countries. In the Netherlands, for example, it is a widely used recreational drug which can be purchased legally in coffee shops. Additionally, two states within the United States - Colorado and Washington - recently voted to approve the recreational sale of marijuana, although it is still unclear what will happen to these laws. And in Denmark there is currently (spring 2013) political pressure to introduce a three year test period, making it legal to buy marijuana from pharmacists in Copenhagen (Politiken, 2013). The inclusion of cannabis in the prohibited list thus creates a moral and policy dilemma for the Anti-Doping Authorities in countries such as the Netherlands because they are required, under the WADA Code, to penalize athletes for taking part in what is, in the Netherlands, a widespread and legal social activity. Not surprisingly, the Dutch Anti-Doping Authority argues that the inclusion of cannabis on the prohibited list undermines its legitimacy and moral authority; it is for this reason that the Authority has in recent years regularly proposed lifting the ban on cannabis. On 29 June 2012, Herman Ram, CEO of the Dutch Anti-Doping Authority, addressed the issue once again:

The use of a substance that is most likely to have a negative impact on athletic performance should not be part of the anti-doping program, especially when its use has been out-ofcompetition. Athletes, being role models to the young, should not be using marijuana nor should they engage themselves in morally objectionable activities such as smoking in their private lives or speeding when driving a car in rural areas. These activities, however, are not doping issues, and they should not lead to the severe doping sanctions.

We would like to ask WADA to try and find a solution that recognises our view (which we know is shared by many other stakeholders) as well as other views that exist in the world regarding the issue of 'cannabinoids and doping'. This might be arranged by changes in the Prohibited List or in other WADA documents, e.g. raising the reporting threshold or changing the sanction regimen in case of a first cannabis offence. From a principal point of view, we feel it is unfair to sanction athletes on the basis of the presence of a long-lasting metabolite in an athlete's sample when this particular substance is only prohibited in-competition (Ram, 2012).

In his statement Ram also alludes to the British Sports Council's second argument against the use of recreational drugs, which relates to the influence of sportspeople as role models; in this context, the Sports Council argues that the 'behavior of elite competitors can have a significant impact on young people as they admire and aspire to emulate their sporting heroes, especially their actions and attitudes.' Again, the argument, as Ram points out, is one which represents a shift away from sport-specific values, for the argument is not that sportspeople who use recreational drugs are contravening the ethics of sport, but that this particular aspect of their non-sporting lifestyle is considered to offend against public sentiments relating to the use of controlled drugs within the society more generally.

This 'spillage' of public attitudes towards drugs in general into the sporting arena is, however, problematic. One of the problems in this respect is that, as we noted earlier, drug use within the wider society has come to be associated with a large number of what are held to be 'anti-social' activities such as a variety of forms of crime and delinquency. As a consequence, the word 'drug', as Black(1996) has pointed out, has come to have a whole variety of negative connotations which have little to do directly with sport but which have undoubtedly 'contaminated' public attitudes and sporting policy 
towards drug use in sport. This 'contamination' of the issue of drug use in sport by wider anxieties about the use of controlled drugs more generally, and of course the associated emotive connotations of the word 'drug', have always been present since the development of modern anti-doping policies in the 1960s, but they have been made particularly explicit by more recently imposed controls on the use of recreational drugs in sport. It is important to recognize this broader context within which anti-doping policy in sport has been made; it is even more important to recognize that this emotively charged context is not one which is conducive to thinking about drug use in sport in a relatively detached way, and not one which is conducive to effective or consistent policy-making in this area. How, then, has WADA tackled this problem?

\section{The WADA Code: a missed opportunity}

WADA was born out of the crisis precipitated by the doping scandal in the 1998 Tour de France (Hanstad, Smith, \& Waddington, 2008). The establishment of a new world-wide anti-doping agency with wide-ranging powers provided a real opportunity for fresh thinking, not just in relation to technical issues concerned with such things as testing procedures, but also in relation to key issues such as the rationales for anti-doping regulations and for the inclusion of some substances and the exclusion of others from the list of banned substances and procedures. Regrettably WADA has for a long time failed to seize this opportunity.

WADA has, in effect, simply taken on board, and in uncritical fashion, the traditional arguments concerning health and fair play as well as the more recent 'catch all' rationale ('embedded in the spirit of sport' criteria) discussed above; the result is that the World Anti-Doping Code (the Code) simply replicates many of the problems associated with earlier anti-doping statements. This is, perhaps, most clearly exemplified in the criteria which it uses to determine which substances can be included on the prohibited list of substances and methods.

Under Section 4.3 of the Code, a substance or method is considered for inclusion on the prohibited list if WADA determines that the substance or method meets any two of the following three criteria: (i) that it has the potential to enhance or enhances sport performance; (ii) that the use of the substance or method represents an actual or potential health risk to the athlete; and (iii) WADA's determination that the use of the substance or method violates the spirit of sport (WADA, 2003, pp. 15-16; WADA, 2009, pp. 32-33).

The fact that a substance or method may be prohibited on the ground that it meets any two of the three criteria reveals an obvious anomaly: that a substance may be banned on the grounds that it damages the health of athletes and is contrary to the vaguely defined 'spirit of sport' even though the substance may have no performance-enhancing effect (also, the 'spirit of sport' includes 'health' as one of its 11 descriptors, resulting in the paradox that if a drug or method is considered unhealthy it in itself meets two of the three criteria). In effect, this regulation means that athletes can be punished under the anti-doping code for a form of behavior - the use of recreational drugs which are not performance-enhancing which is not cheating and which does not constitute 'doping' in any meaningful sense of the term.

This subtle shift massively extends WADA's reach. As noted earlier, the original rationale for anti-doping policy addressed two key sporting values: fairness and the health of athletes. Although there may be disagreement over the degree to which these provide a clear rationale for anti-doping policy, these two concerns unquestionably relate to important issues in sport. But WADA has clearly used the 'spirit of sport' argument to reach beyond traditionally accepted sporting concerns. In this regard, it is clear that WADA's third criterion for inclusion - that the use of drugs is against the vaguely defined 'spirit of sport' - performs the same function as the Sports Council's argument, noted earlier, that the use of drugs is 'harmful to the image of sport': it provides an argument for the banning of recreational drugs whose use cannot be banned on grounds of performance-enhancement. In this regard, WADA is, in effect, using anti-doping regulations to police personal lifestyle and social activities which are unrelated to sporting performance. This action - regulating aspects of athletes' behavior that are unrelated to the sporting contests - is both unprecedented and morally problematic.

The basis on which sporting authorities claim the right to regulate the private lifestyles - as opposed to the sporting activities - of athletes is unclear and, indeed, this claim was questioned by a key working group which was established by the IOC itself in 1998. Prior to the 1999 Lausanne World Conference on Doping in Sport, which the IOC convened and which led to the establishment of WADA, the IOC appointed four working groups to prepare reports for that conference. The Report of the Working Group on the Protection of Athletes noted that:

While the IOC has a strong interest in preserving the fairness of Olympic competition, and while it has strong grounds in sport ethics for seeking to eliminate doping, it is on far riskier ground if it seeks to mandate moral rules unrelated to sport. It is not clear why sport, or the Olympic Movement, should be part of a general campaign to eliminate, for instance, marijuana use. If sport federations or the IOC wish to take a stand against recreational drug-use (or tobacco, or alcohol abuse, or other social problems) then this should be done through codes of conduct rather than rules that govern sport. (IOC, 1998)

The sports philosophers Angela Schneider and Robert Butcher the former an Olympic medallist and former member of WADA have been even more direct in their comments. They argue:

Quite simply, the IOC has no good grounds for including marijuana on a restricted list, or for testing for its use. The mandate of the IOC for drug testing is to ensure that athletes compete fairly. The rules against drug use are to ban performance-enhancing substances - marijuana is not a performance-enhancing substance, so the IOC has no business testing for it.

Some people might argue that the use of marijuana is illegal (and perhaps also immoral) and so the IOC is justified in testing for its use. But what possible grounds are there for suggesting that the IOC has a role in enforcing the law? The IOC is a sports organization, not a law-enforcement agency. Similar arguments apply if we suggest that the IOC has a role to play in enforcing morals. In all sorts of areas, community moral standards are contested and open to debate. There are many people throughout the world who believe that homosexuality is morally wrong yet it would be both absurd and immoral to suggest that the IOC has a role in testing for, and prohibiting from competition, anyone who has engaged in same-sex sexual activity. (Schneider \& Butcher, 2001, p. 132)

More recently, in his evidence to a House of Commons Select Committee in 2007, the then British Minister of Sport, Richard Caborn, echoed these concerns. Asked about the use of recreational drugs by athletes, Caborn said: 'What is WADA there for? WADA is there to root out cheats in sport. That is their core business'. It was not, he argued, part of WADA's role to be in the 'business of policing society' (House of Commons, 2007, p. Q.321).

This issue has recently been the focus of media attention following the expulsion of an American judo player, Nick Delpopolo, from the London 2012 Olympics after he tested positive for marijuana. Commenting on the exclusion of Delpopolo, Michael Joyner, a physiologist at the Mayo Clinic in Minnesota, was quoted as 
saying, 'It's hard to imagine how smoking a joint or eating marijuana brownies is going to help somebody in judo' and he added, 'My advice to WADA is that they should focus on drugs that are clearly performance enhancing'. This view was echoed by David Nutt, a professor of neuropsychopharmacology at Imperial College London, who argued: 'There's no evidence cannabis is ever performance enhancing in sport, and since its use is legal in a number of countries, there's no reason for it to be banned by WADA'. He added that, since it is not performance enhancing, 'It seems ludicrous that someone could quite legally smoke cannabis in Amsterdam in the morning and then come over to London in the afternoon and be banned from competing'.

Significantly, a growing number of organizations representing elite athletes have also criticized the ban on cannabis. In May 2012, the Coalition of Major Professional Sports in Australia called for marijuana to be removed from the list, arguing that marijuana should not be grouped with drugs, like human growth hormone and steroids, which are clearly performance enhancing (Kelland, 2012). In their WADA Code Review, EU Athletes (which represents 100 player unions and more than 150,000 European athletes) stated that: 'Cannabis made up 18.7\% of reported violations in Europe in 2009 using up valuable resources that could have been targeted at real doping cheats. It should be removed from the list' (Palmer \& Baer-Hoffmann, 2012). The Danish Elite Athletes' Association has similarly argued that social drugs 'which are not performance enhancing should be removed from the list' (Blæsild, 2012, p. 5).

\section{Anti-doping: time for a more focused approach?}

We support these calls for the removal of non-performance enhancing 'recreational' drugs, such as marijuana, from the WADA list of prohibited drugs. However, it would be wrong to see this - as some people might be inclined to see it - as a policy recommendation which is 'soft' on drug use in sport; the critical question is not whether any specific policy can be seen as either 'hard' or 'soft' on drugs but, rather, whether it is an appropriate response to the problem. In this regard, we would suggest that an appropriate policy should meet two criteria: firstly, it should have a clear and reasonable rationale and, secondly, the implementation of that policy should lead to the more effective control within sport of those drugs which are performance enhancing.

In relation to the first criterion, we have argued above that there is no clear sport-related rationale for banning, within a sporting context, the use of drugs such as marijuana. In those countries in which marijuana use is illegal, the enforcement of the law is a matter for the police, not for sporting bodies. Organizations such as WADA have no more right to discipline athletes for the use of illegal drugs than they have to discipline athletes for shoplifting, dangerous driving or any other criminal activity; as Schneider and Butcher have noted, sporting organizations are not law enforcement agencies, and such activities are not a legitimate part of WADA's remit. And neither are sporting organizations the appropriate bodies for enforcing morals; again, WADA has no more right to discipline athletes for the use of non-performance enhancing - but what some people may see as 'immoral' - drug use than it has to discipline athletes for any other forms of what might be considered 'moral turpitude', such as what might be held to be sexual 'deviance'.

But, secondly, we are also concerned that the ban on drugs such as marijuana draws WADA away from its legitimate focus and thereby hinders the effective implementation of anti-doping policies. WADA's budget for 2012 is a little over US $\$ 26 \mathrm{~m}$, which is a very limited budget for an organization with global responsibilities; as a comparison, the annual turnover of a medium sized English university, such as the University of Leicester, is $£ 230 \mathrm{~m}$, roughly thirteen times as much. WADA is clearly not over-endowed with resources and this makes it even more important that it focuses its scarce resources on those areas which constitute its core functions.

The expenditure of scarce resources policing the use of 'social' drugs such as cannabis is a matter which clearly concerns some of those charged with the responsibility of enforcing the WADA Code. Thus Tim Lythe of the New Zealand Federation of Athletes has pointed out that anti-doping organizations expend a lot of resources on policing 'low (or no) risk substances such as cannabis' and he suggests that the WADA Code 'needs to refocus its resources around detecting those athletes who are genuinely and systematically cheating the system' (Various Authors, 2012, p. 4). A similar point has been made by Graeme Steel, Chief Executive of Drug Free Sport New Zealand, who has stated that 'there is a strong and valid argument that dealing with cases involving cannabis use ... is a significant misallocation of ADO resources' (Various Authors, 2012, p. 33).

We agree. The inclusion of drugs such as cannabis in the banned list unnecessarily burdens WADA with testing for, and sanctioning athletes who use, substances that do not enhance sporting performance. And this is a not insignificant burden; in 2011, cannabinoids and cocaine amounted to 485 , or $8.6 \%$, of the total 5600 adverse analytical findings (WADA, 2011, Table E). Prosecuting these cases diverts WADA's scarce resources away from its real task: the detection of drugs which are performance enhancing and which therefore offer those who use them an unfair advantage over their fellow competitors.

WADA's focus and resources should return to enforcing sporting values related to doping rather than policing athletes' lifestyles. The 'spillage' of public attitudes and anxieties about drug use within the wider society into the world of sport has led to the emotively charged sanctioning of recreational drug use by athletes which is not conducive to effective or consistent policy-making in this area. If WADA genuinely seeks to promote healthy and fair sport, its efforts and resources ought to focus exclusively on substances that confer performance-enhancing benefits and not on policing athletes' non-sporting lifestyles.

\section{Conflicts of interest}

The authors have no conflicts of interest.

\section{Acknowledgement}

There was no financial assistance with the project.

\section{References}

Australian Sports Commission. (2004). Australian Sports Commission, 2004 antidoping policy. Belconnen Act: Australian Sports Commission.

Black, T. (1996). Does the ban on drugs in sport improve societal welfare? International Review for the Sociology of Sport, 31, 367-384.

Blæsild, K. (2012). 2015 code review - First code consultation phase. http://www. spillerforeningen.dk/basis/files/DEF-hearing.pdf. Accessed 14.10.12

Conlee, R. (2002). Cocaine. In M. Barhke, \& C. Yesalis (Eds.), Performance-enhancing substances in sport and exercise (pp. 279-288). Champaign, IL: Human Kinetics.

Council of Europe. (1989). No 135A, anti-doping convention. Strasbourg: Council of Europe.

Dimeo, P. (2007). A history of drug use in sport 1876-1976: Beyond good and evil. London: Routledge.

Donohoe, T., \& Johnson, N. (1986). Foul play: Drug abuse in sports. Oxford: Blackwell.

Coakley, J. (2007). Sports in society: Issues and controversies (7th ed., pp. ). Boston, MA: Magraw Hill.

England Hockey. (2005). Sport science and medicine team. http://www englandhockey.co.uk/core_files/fileDownload(228)doc. Accessed 29.05.07

Evald, J. (2009). Retlige grænser for dopingkontrol. In A. V. Christiansen (Ed.), Kontrolsport - Big brother blandt atleter og tilskuere (pp. 71-88). Odense: Syddansk Universitetsforlag.

Hanstad, D. V., Smith, A., \& Waddington, I. (2008). The establishment of the World Anti-Doping Agency: A study of the management of organizational change and unplanned outcomes. International Review for the Sociology of Sport, 43(3), 227-250. 
Houlihan, B. (2002). Dying to win: Doping in sport and the development of anti-doping policy (2nd ed., pp. ). Strasbourg: Council of Europe.

House of Commons (HC). (2007). Science and technology committee, human enhancement technologies in sport, second report of session 2006-07, HC 67. London: The Stationery Office.

International Olympic Committee (IOC). (1989). List of doping classes and methods 1989. Lausanne: IOC.

International Olympic Committee (IOC). (1989). Report of the working group on the protection of athletes. Lausanne: IOC.

International Olympic Committee(IOC).(1999). Olympic movement anti-doping code. Lausanne: IOC

Kayser, B., Mauron, A., \& Miah, A. (2005, December). Viewpoint: Legalisation of performance-enhancing drugs. Lancet, 366, S21.

Kelland, K. (2012). Should sport ban cannabis? http://www.reuters.com/londonolympics-2012/articles/swimming/2012/08/06/performance-enhancing-dopeshould-sport-ban-cannabis. Accessed 26.09.12

McCrory, P. (2007). The drug wars. British Journal of Sports Medicine, 41(1), p1.

O'Leary, J. (2001). The legal regulation of doping. In S. Gardiner, M. James, J. O'Leary, R. Welch, I. Blackshaw, S. Boyes, \& A. Caiger (Eds.), Sports law. London: Cavendish.

Palmer, W., \& Baer-Hoffmann, J. (2012). WADA code review - First submission. http://www.spillerforeningen.dk/basis/files/EUAthletes\%20WADA.pdf. Accessed 14.10.12

Politiken. (2013). København vil have fri hash - igen (Copenhagen wants legalised hash - again), 14.01.2013, reporter: Signe Grejsen Nissen. http://politiken.dk/politik/ECE880087/koebenhavn-vil-have-fri-hash-igen/. Accessed 19.03.13

Ram, H. (2012). Netherlands reaction to draft 2013 Prohibited List International Standard. http://www.dopingautoriteit.nl/media/ files/Allerlei/NED_comments_to_Prohibited_List_2013.pdf. Accessed 22.11.12

Retsinformation. (2004). (Act on promotion of doping-free sport) Lov om fremme af dopingfri idræt. , 1438. Ref Type: Bill/Resolution.
Schneider, A., \& Butcher, R. (2001). An ethical analysis of drug testing. In W. Wilson, \& E. Derse (Eds.), Doping in elite sport. Champaign, IL: Human Kinetics.

Sparre, K. (2011). 'New study claims doping is bigger threat to sport than match-fixing', play the game. http://www.playthegame.org/news/detailed/ new-study-claims-doping-is-bigger-threat-to-sport-than-match-fixing-5302. html. Accessed 12.10.12

Sports Council. (1996). Report on the sports council's doping control service, 1995-96. London: Sports Council.

Sports Council. (1998a). Ethics and anti-doping directorate, annual report, 1997-98. London: UK Sports Council.

Sports Council. (1998b). Competitors and officials guide to drugs and sport. London: UK Sports Council.

Various Authors. (2012). 2015 code review - First code consultation phase. http://www.wada-ama.org/Documents/World_Anti-Doping_Program/WADPThe-Code/Code_Review/Code\%20Review\%202015/WADA-Code-Review-20151st-Consultation-General-Comments.pdf. Accessed 14.10.12

Verokken, M. (2005). Drug use and abuse in sport. In D. Mottram (Ed.), Drugs in sport. London: Routledge.

Whitebread, C. (1995). 'The history of the non-medical use of drugs in the United States', speech to the California Judges Association 1995 annual conference. http://www.druglibrary.org/schaffer/History/whiteb1.htm. Accessed 19.11.12

World Anti-Doping Agency (WADA). (2003). World Anti-Doping Code. Montreal: WADA.

World Anti-Doping Agency. (2009). World Anti-Doping Code. Montreal: WADA.

WADA. (2007). The 2008 prohibited list. Montreal: WADA.

WADA. (2011). The World anti-doping laboratory 2011 laboratory testing figures. http://www.wada-ama.org/Documents/Resources/Testing-Figures/WADA2011-Laboratory-Testing-Figures.pdf. Accessed 05.10.12.

Waddington, I., \& Smith, A. (2009). An introduction to drugs in sport: Addicted to winning? London: Routledge. 